\title{
Understanding and Interpreting the Concept of Malaysian Garden Design: Experts Conferring
}

\author{
Ahmad Zamil Zakaria, Melasutra Md Dali, Hazreena Hussein
}

\begin{abstract}
This paper sets out to define and describe the definition of the concept of the Malaysian Garden by referring to the landscape and garden experts in Malaysia. It will focus on the expert's understanding, knowledge and experience about this concept. Researchers used qualitative research methods that involved semi-structured in-depth interviews and observations. The respondents for this study are Malaysian Garden concept experts who have been certified by the National Landscape Department (NLD) of Malaysia, referring to the books published by them in 2009. At present, it is difficult to obtain a strong and firm Malaysian Garden concept definition. As a result of this study, all these experts provide different definitions. It is due to a different profession and work experience factors. In this study, the researchers have also gained their insights on the method of branding the concept, aiming to introduce it to local and global communities. Through this research, it helps the responsible party in creating this concept to understand better and be sensitive to the subject. However, further research should be carried out to enable the concept that has been created to satisfy all stakeholders. The study has stated an argument, why the Malaysian Garden concept is still not going to its branding. If it has been introduced to the public, we need to know how to uphold it as a national identity. This research paper will attract attention from stakeholders in Malaysia, industry players, academics and landscape architecture students.
\end{abstract}

Keywords: Branding, landscape architecture, Malaysian identity, Malaysian garden.

\section{INTRODUCTION}

The concept of the Malaysian Garden has been raised since 1997 when the General Director of the National Landscape Department (NLD) has expressed a desire to come up with a concept that could represent the design of Malaysian community parks in the future [1]. It is in line with the NLD's vision; "To lead and to be centric of excellence for landscape development in achieving the quality and sustainable living environment with the Malaysian identity" [2]. There are several initiatives that the NLD has taken to improve the department's vision. Among the activities presented was the organizing of the Malaysian Park Seminar in 2005 and 2007. In 2006 in collaboration with Malaysia's leading landscape firm Morphosis Design Sdn. Bhd., NLD participated in an international landscape exhibition to showcase the design of the Malaysian Garden. It was a good initiative by the NLD to introduce the concept of Malaysian Garden at that time.

From 2006 to 2008, a study of the Malaysian Garden Design Guidelines was conducted "in-house" by the NLD

Revised Version Manuscript Received on September 16, 2019.

Ahmad Zamil Zakaria, Universiti Teknologi MARA Perak Branch, Perak, Malaysia.

Melasutra Md Dali, Center for Sustainable Urban Planning and Real Estate, Faculty of Built Environment, Universiti Malaya, Malaysia.

Hazreena Hussein, Center for Sustainable Urban Planning and Real Estate, Faculty of Built Environment, Universiti Malaya, Malaysia.
[3]. The NLD successfully published a guidebook of the Malaysian Garden Guidelines in 2009. The book is called "Taman Malaysia Untuk Diwarisi / The Malaysian Garden to be inherited" [4]. A vital component of the Malaysian Garden concept is to implement the features of the Malay Garden, as agreed in the Malaysian Garden Seminar [5]. To develop the Malay Garden, a designer must emphasize such things as community identity, the architectural features, culture and philosophy of the nation [6].

In 2010, Tourism Malaysia (a government agency under the Ministry of Tourism Malaysia) participated in a landscape design competition at the Chelsea Flower Show, London. The design concept was named "Malaysian Tropical Garden", and it has won a gold medal in the competition [7]. A year later, in 2011, Tourism Malaysia again entered the same competition by introducing the concept of "Traditional Malay Village" [8]. It has once again seen the design of the park representing Tourism Malaysia winning the gold medal. Its means that the concept of Malaysian Garden is internationally accepted and has the potential to be developed. At that time, the activities of developing the Malaysian Garden concept were very positive. Besides, it needs an added value to survive in the landscape architecture industry.

Tourism Minister Datuk Seri Dr Ng Yen Yen said the victory at the Chelsea Flower Show had given the ministry the encouragement, confidence and commitment to do the best in the art of designing the park. It has the potential to be a new tourism product. She added, "Ecological tourism has a potential market which is yet to be developed, and many European tourists are very interested in visiting gardens and flower expos" [9]. So, what is the status of the Malaysian Garden concept today? Is it still relevant? What is the true definition of the Malaysian Garden concept? Has the Malaysian Garden Design Guide been used to design public gardens today? The last question, do we need for rebranding the Malaysian Garden concept?

\section{METHOD AND MATERIALS}

Researchers have used qualitative research techniques. Sample selection of the study was made using Simple Random Sampling (SRS) method. The criterion for selecting respondents was to use the Purposeful Sampling (PS) technique [10]. A PS involves identifying and selecting individuals or groups of individuals that are exceptionally knowledgeable about or experienced with a phenomenon of 
interest [11]. Researchers have used semi-structured in-depth interviews and observations to obtain data. The main goal of qualitative data analysis is to uncover emerging themes, patterns, concepts, insights, and understandings of an issue [12]. A total of six (6) respondents were interviewed with a range of 45-60 minutes/person/ session.

The criteria set out in the selection of respondents are as follows:

1. The Malaysian Garden concept specialist: There are 21 names in the list referring to the basic guidelines of the concept of the Malaysian Garden [4].

2. The representative of academic and industry players (consultant and contractor), policymaker.

3. Former Director-General of government agencies, which is responsible for ensuring the landscape architecture industry in Malaysia, is progressing.

\section{RESULTS AND DISCUSSION}

This paper set out to describe the interviewing activity of the respondents was conducted between January - December 2018. It took a long time because it required the researchers to make an appointment with the respondents to hold an interview session. In order to achieve this purpose, researchers do not force or give dates to respondents to avoid pressure on them. It may harm the results of this study. Researchers will not disclose the names of respondents in this paper for their privacy and security.

What is the status of the Malaysian Garden concept today?

The first part of this study is to investigate the status of the Malaysian Garden concept in landscape architecture, referring to the latest scenario. Some respondents argue that there has never been a park that uses the Malay Garden concept in Malaysia today. So, they think no Malaysian Garden concept has ever been implemented in any garden that has been developed by any party. Some respondents stated that the Malaysian Garden concept had been used for a long time in the project. The respondent insisted that the concept of the Malaysian Garden should make Malaysia's identity clear.

Some respondents said if we asked the students, do they want to explore the concept of cultural landscape, Malay Garden concept or Malaysian Garden concept in their project? The answer is no. It is because of the lack of reference on the topic. Also, not the area of interest of the younger generation. So, the status of the Malaysian Garden concept is very vague because stakeholders do not advocate it. In a general sense, we are focusing on that, returning to our satisfaction of implementing it, but of course, the current 'trend' will determine whether it is necessary or not. In other words, there is no longer a Garden of Malaysia, and that is why we need the Malaysian Garden Design Guidelines, and the NLD has issued it. We need to make it a trend to be loved by all. How to make it trend? It requires the efforts of various parties in this field.

\section{Is it still relevant for today scenario?}

The impact of the Malaysian Garden is a park whereby it belongs to the whole public. The impact of the Malaysian Garden is a park whereby it belongs to the whole public. Therefore, each criterion will be representing the whole community in Malaysia. Some respondents think that Malaysian Garden will represent the whole ethnicity and needs an excellent feature that we can bring the ethnic together. It is still relevant; we cannot please everyone, not everyone we can satisfy, because our interests and way of life are out of control. It is very subjective, but able to be achieved.

Some respondents think it is still relevant because the future trend of landscape architecture is "bringing nature and wildlife". Perhaps this trend has little to do with the concept of Malaysian Garden or Malay Garden. So, if we see the benefits, especially in terms of how we elevate ourselves, who we are and our identity, it will indirectly lead to economic resilience through tourism, through commodities related to cultural heritage and in turn will be a learning centre and knowledge related to the Malays especially. Indeed, for us to build the identity of the future and the present, this is the opportunity for us to reinvent ourselves with policies that promote Malay culture as a Malaysian identity.

In particular, we see that the concept of Malaysian Garden or Malay Garden can have an impact on everyone. When we talk about the impact on the country, we will discuss more the inclusion of tourists into our country, cherishing our cultural heritage and so on. If we talk about education, we will talk about the new bridge learning about what is our history. We need to promote Malaysian products, and it will give back to the nation as well as the people. The added values can come after that; for example, we create an identity. That is National Identity and can make it history. History can be a product of tourism; it can be the level of achievement of civilization; that is why we have to do that.

What is the true definition of the Malaysian Garden concept?

There are inconsistent views on the themes that need to represent the Malaysian Garden concept. Some of the respondents said that the Malay Garden model does not necessarily apply to the design of the Malaysian Garden concept. Some respondents said, "Therefore, I would say that the identity of the nation should be greenery and that is the Malaysian Garden". Refer to the issue raised by this respondent, concerning the size and space of the appropriate placement of two concepts. According to this respondent, the concept of Malay Garden is always used in home planning which is generally in term of space planning that front garden, side and orchard on the back) and it is a private space. For the Malaysian Garden concept, it means extensive gardens and for everyone's use, regardless of ethnicity. It is biased if only the Malay culture is incorporated into the design of the Malaysian Garden.

There is a view of the respondent that the emotional and representational components in the identity of Malay Garden must be Malay elements, but we call it the "Malaysian Garden" because Malaysia is a multi-racial country. The respondent also asserted, "I would rather call it the Malaysian Garden than Malay Garden." Although the inspiration and ideas we have gained from Malay culture. The intangible

Published By: 
elements refer to the uses of Malay elements in the design.

Some respondents said that it was within the expected level, the Malaysian Garden, which is a Malay Garden if we saw it here in terms of the use of plants, wood elements and others. Therefore, we can see how this aspiration brought back the glory of the Malay tradition and the Malay Sultanates in the past. We can bring back the idea of wild nature because if it looks at the root of the tropical landscape, it is like the Malay Garden concept that comes from the village. If we want to directly do what our ancestors did 100 or 200 years ago to implement in the lives of the people in Kuala Lumpur today, it is impossible. It is not appropriate, and that is why the adaptation of the design is essential, but it should not be overlooked in the features and details of the Malay Garden itself.

In order to better understand the concept of Malaysian Garden, it is necessary to follow the Malay Garden identity. Malay culture in ancient times, this is what makes this concept different from the others. We must agree that Malaysian Garden should adopt this identity. When we talk about identity, it also goes with a trend of the day.

Some respondents felt that the Malaysian Garden should cover a bigger scale. In the guidelines that the NLD does, some many Malay principles or elements must be applied. Some respondents did not fully agree with this, as it involved a process that everyone had to accept, unfortunately in Malaysia, it is quite tricky because we are a pluralistic society. There is no issue or problem to say that the Malay Garden is part of the Malaysian Garden. However, it is vital that we further develop the guidelines of the Malaysian Garden so that no issues are raised during the design process.

Have the Malaysian Garden Design Guidelines been used as a basis for designing public gardens today?

As a result of the interviews conducted, most respondents did not realize that the NLD had issued these guidelines. That is dissatisfaction because they were the team that was formed to create these guidelines in the first place.

One of the respondents stated that he had been introduced the Malaysian Garden concept for 18 years; however, the way he implemented it was from his perspective. He added that there were guidelines from the parties responsible for following and if any, he did not know. There is no promotion carried out by them, and it would not be surprising if the concept were not recognized. Merely, he still uses most of the elements derived from the culture and lifestyle of the Malays, which is a certainty in his design. It was not a big problem for the respondent as he was raised in a Malay village.

Most often, the funder for the development of public parks in Malaysia is NLD, a concept similar to the Malaysian Garden applied to Cempaka Lake Garden, which was already developed in the early 2000s. There are other examples like Permaisuri Lake Garden, development by The Kuala Lumpur City Hall. The design created in the centre has a 'U' shaped area, which symbolizes Malay women's bunny. It was adapted from the bun used by the Queen of Pahang and from there the Garden was named. Both parks are examples of parks that existed before these guidelines were issued.

One of the respondents said: "I had implemented the Malaysian Garden concept at domestic and overseas garden exhibitions before the NLD published the guidelines. However, it has been discussed, and I am one of those panels. I do not know what the status of these guidelines is after the end of the seminar."

The main challenge is how to complete the Design Guidelines and overcome the weaknesses in planning and distribution. Not many people know about the existence of these guidelines, so who is to blame for this issue. The NLD does not play a role as the organization responsible for carrying out the task. We have identified the cause of people's failure to know or the problem of introducing them. To this end, there is a suggestion from the respondent that it is believed to be able to address this issue further. He proposes to develop a 20-acre public park by implementing the Malaysian Garden concept. Use all the criteria and elements as contained in the guidelines. It is to facilitate the understanding of the community and designers about the concept. The public must accept the criteria we propose if it is accepted; this means there will be no problem to design another Malaysian Garden in the future. The importance is, all the criteria for the design of the park must be clear and without a doubt.

Is the Malaysian Garden concept necessary for rebranding in the future \& RESULT

From the interviews conducted, the researchers found that the Malaysian Garden concept needed rebranding activities. The basis of this proposal was that all respondents agreed that the concept of Malaysian Garden existed even without reference to guidelines published by the NLD. However, the lack of guidelines at the time made it difficult for designers to standardize the elements of the Malaysian Garden concept Recently, designers have taken the approach of designing the Malaysian Garden concept according to their understanding. It has been proven by the existence of several Malaysian Garden concepts as created by landscape-based companies, Terra Garden Sdn Bhd and Morphosis Design Sdn Bhd.

The literature review reveals further that, branding often aims at reducing the multitude of consumers' image associations, thus trying to communicate clear verbal and visual images. For many product brands, this strategy works quite well, since consumers most often are neither willing nor able to remember complex or diverse associations for one product' [13] The concept of rebranding is associated with brand renewal, refreshment, makeover, reinvention, renaming and repositioning of an existing brand [14]. According to them, the principles of rebranding need to cover the brand vision, bridging the existing brand, meeting the need for new markets, brand orientation and; integration/coordination of strategy. To rebrand the Malaysian Garden concept can be adapted from the 'Conceptual Rebranding Circle' produced by [15] (see Fig. 1) 


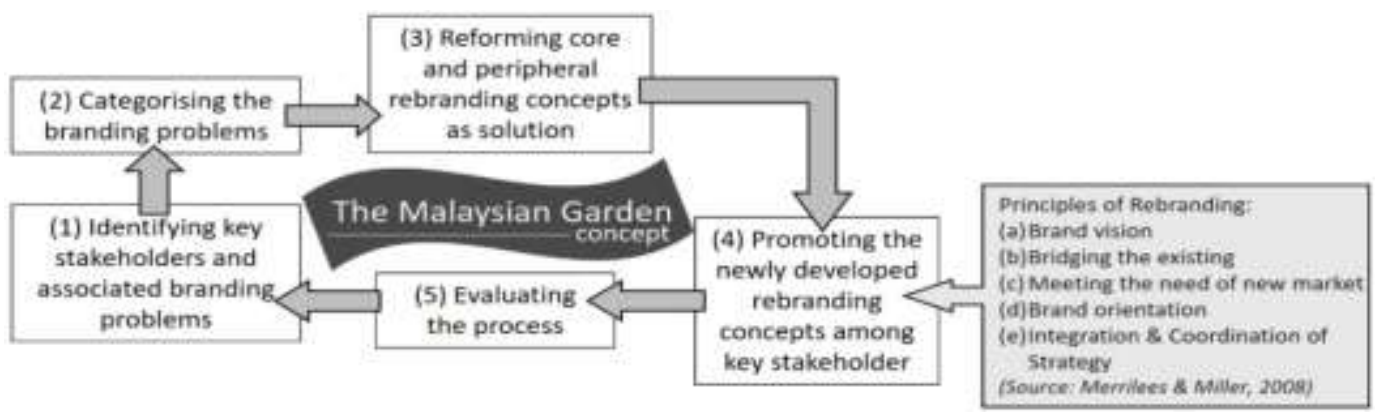

Fig. 1: A Conceptual Rebranding Circle [15]

\section{CONCLUSION}

Although several different views of definition by the respondents, they agreed that the concept of the Malaysian Garden had been around for a long time, but it has different directions depending on who defines it. Among the definitions of the concept of the Malaysian Garden given are (1) the Malaysian Garden should use the traditional elements of the Malays, (2) the Malay Garden does not necessarily mean the Malaysian Garden due to the different design requirements, and (3) the Malaysian Garden should be able to represent all is the leading ethnic group in the country, and it cannot focus on just one ethnic group. Likewise, looking at the definitions that have been presented, it is found that some of the Malaysian Garden concept experts appointed by the NLD are not in line with what was resolved at the Malaysian Garden Seminar held in 2005 and 2007.

However, a vital component of the Malaysian Garden concept is the need to implement the features of the Malay Garden as agreed in the Malaysian Garden Seminar [16]. The issue that has been highlighted here is that our people today do not appreciate anything close to them. Although it is beautiful and comparable to anything else in the world, we do not appreciate it, and as such we are more accepting of external identities than what we have [18].

As a result, the concept of Malaysian Garden existed but was not compromised by guidelines and lacked the support of stakeholders. Referring to the diagram below, the concept of the Malaysian Garden is currently undergoing a 'Dormant Period' which means that there has been no development and competitiveness in a long time. Thus, some of the respondents thought that the concept of Malaysian Garden was implemented, but its existence was still vague as the design was not reliable due to the lack of specific guidelines.

Some have argued that financial factors are one of the reasons why the Malaysian Garden concept cannot be implemented more systematically. Besides, respondents from the academic background stated that students today are also less interested in exploring the theme of cultural landscapes during their studies. It may be due to lack of references (no physical evidence) as well as deficiency of a study conducted by previous researchers. In short, some views link it to the lack of emphasis/support of the ministry (government agencies/policymakers) by classifying it as one of the most irrelevant developments to be undertaken today.

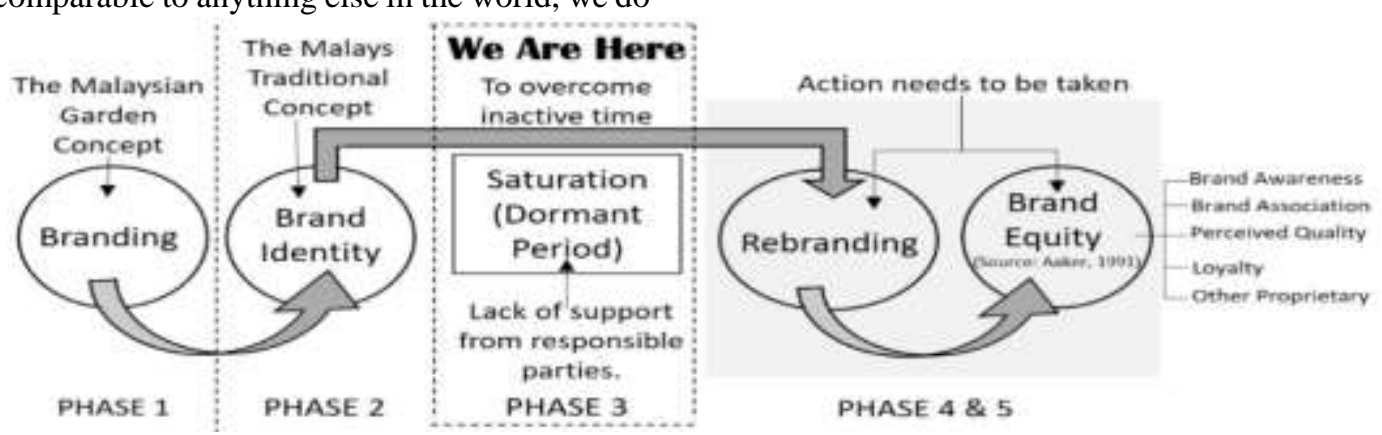

Fig. 2: Status of the Malaysian Garden concept

Finally, rebranding is a possible way to conduct activities to re-introduce the concept of the Malaysian Garden in the future. If a change in marketing aesthetics can be undertaken to alter customers' (users, designers and stakeholders) negative perceptions of the company (in this case the researchers used the Malaysian Garden Concept as a subject matter), shows changes to more positive motives such as internationalization and glocalization can trigger a rebranding exercise [17].

By rebranding, it helps to showcase new brands without compromising on the existing identities, being able to meet market demands, having marketing strategies, and promoting innovation and creativity in the field of heritage landscape design. The concept of the Malaysian Garden can be developed in the future with the attention and support of various stakeholders involved in the development of landscape architecture in Malaysia. It will show the importance of disseminating information, knowledge and understanding of this concept to landscape designers, which will indirectly facilitate the design process. Also, we need to expand the series of in-depth research by academia and government agencies to demonstrate their seriousness in upholding this concept. 


\section{ACKNOWLEDGMENT}

We would like to express our gratitude to the Research Management Institute (RMI), Universiti Teknologi MARA, for granting full trust to us to do this research. Special thanks to our sponsors of MOHE-Fundamental Research Grant Scheme (FRGS) for providing an adequate provision for this project. Thanks also to the Center for Sustainable Urban Planning \& Real Estate, Faculty of Built Environment, University of Malaya (SUPRE), the Centre for Knowledge and Understanding of Tropical Architecture and Interior (KUTAI) and Taman Alam Melayu Nusantara (T.A.M.A.N) UiTM Perak Branch for the invaluable support during the research period.

\section{REFERENCES}

1. F. Ismail, Designing the Malaysian garden. Available: http://library.perdana org.my/Digital_Content/Prominent_Leaders/Mahathir/Ne ws_1968-2004/1996-1998/1997aj/designing\%20the\%20 malaysian\%20garden.pdf.

2. National Landscape Department, Introduction. Available: http://www.jln.gov.my/index.php/ pages/view/2.

3. National Landscape Department, Annual report 2008 Available: http://www.jln.gov.my/resources/index/user_1/Text $\% 20$ Documents/Dokumen\%20Penerbitan/Laporan\%20Tahun an\%20JLN\%202008/LAPORAN_TAHUNAN_2008_4.p df.

4. National Landscape Department, Taman Malaysia untuk diwarisi (The Malaysian garden to be inherited). Putrajaya: Ministry of Housing and Local Governance, 2009.

5. J. Abu Bakar, Taman Malaysia ke Arah Identiti Nasional (The Malaysian Garden Towards a National Identity). Johor: UTM Press, 2012.

6. A. Z. Zakaria, I. H. Salleh, S. N. Harun, and M. S. A. Rashid, "Preservation characteristics of Malay Garden: A catalyst for sustainable cultural landscape in Malaysia," International Colloquium of Art and Design Education Research, 2016, pp. 265-276.

7. Tourism Malaysia Media Release, Malaysia tropical garden wins gold at Chelsea Flower Show 2010. Available:

https://www.tourism.gov.my/pdf/uploads/media/pr\%20c helsea\%20flower\%20show.pdf.

8. Tourism Malaysia Media Release, Gold again for Tourism Malaysia Garden in Chelsea. Available: https://www.tourism.gov.my/media/view/gold-again-fortourism-malaysia-garden-in-chelsea.

9. Star Online, Tourism Ministry to focus on promoting eco-tourism. Available: https://www.thestar.com.my/ news/nation/2010/06/13/tourism-ministry-to-focus-on-pr omoting-ecotourism/\#2wqEm0YOk4vko2 Vq.99.

10. D. S. Moore, G. P. McCabe, and A. Bruce, Introduction to the Practice of Statistics. New York: WH Freeman and Co., 2012.

11. J. W. Cresswell and V. L. P. Clark, Designing and Conducting Mixed Method Research. California: Sage Publications, 2011.

12. M. Q. Patton, Qualitative Research and Evaluation Methods. California: Sage Publications, 2002.

13. K. L. Keller, "Conceptualizing, measuring, and managing customer-based brand equity," Journal of Marketing, 57(1), 1993, pp. 1-22.

14. B. Merrilees and D. Miller, "Principles of corporate rebranding," European Journal of Marketing, 42(5/6), 2008, pp. 537-552.

15. E. Gide and S. M. R. Shams, "An analysis of the rebranding opportunity against the contemporary challenges of Australian International Education Industry," Academy of Marketing Science 7th Global Brand Conference on Brand, Identity and Reputation: Exploring, Creating New Realities and Fresh Perspectives on Multi-Sensory Experiences, 2011, pp. 217-219.

16. D. Aaker, Managing Brand Equity: Capitalizing on the Value of a Brand Name. New York: Free Press, 1991.

17. L. Muzellec and M. Lambkin, "Corporate rebranding: Destroying, transferring or creating brand equity?" European Journal of Marketing, 40(7/8), 2006, pp. 803-824.

18. A. Z. Zakaria, M. S. A. Rashid, and S. Ahmad, "Hardscape and softscape elements of a Malay garden," Pertanika Journal of Social Sciences and Humanities, 25, 2017, pp. 109-118. 